\title{
Long-term monitoring of aircrew exposure onboard of Czech Airlines aircraft
}

\author{
O. PLOC ${ }^{1,2}$, F. SPURNÝ ${ }^{1}$
}

(Manuscript received 29 June 2006, accepted 6 November 2006)

ABSTRACT This contribution presents new results related to the aircraft crew exposure onboard aircraft of Czech air companies. First, the results of long term monitoring onboard of an aircraft of Czech Airlines are presented. In the period May-December 2005, 494 individual flights have been followed using MDU-Liulin Si-diode based spectrometer, together with thermoluminescent and track detectors. The results of measurements are analyzed and compared with those of calculation performed with CARI6 and EPCARD3.2 codes. Monitoring period represented about 4.6 times more than usual annual engagement of an aircrew (600 hours). Total effective dose during these 2755 hours was between 11 and $12 \mathrm{mSv}$, following the considered method of evaluation. Both the measuring and calculation methods correlate well. This fact leads to confirmation of the routine method evaluating the level of aircraft crew exposure using CARI6 code as correct for this purpose. Second, the results of individual monitoring of aircrew members obtained during few last years by this routine method are presented; general tendencies of aircraft crew onboard exposure of Czech air companies are outlined. The contribution of aircrew exposure to total occupational exposure in the Czech Republic represents about $20 \%$.

Keywords: cosmic radiation / aircraft crew exposure and monitoring / Si-detector / energy deposition spectrometer

RÉSUMÉ Monitorage à long terme de l'exposition du personnel navigant à bord d'un avion de la compagnie aérienne Czech Airlines.

Cette contribution présente de nouveaux résultats concernant l'exposition aux rayonnements cosmiques du personnel navigant de la compagnie Czech Airlines. Les résultats d'un monitorage à long terme sont présentés dans un premier temps. Entre les mois de mai et décembre 2005, des mesures ont été réalisées au cours de 494 vols individuels. En complément des dosimètres thermoluminescent et à traces habituellement utilisés, un spectromètre silicium de type MDU-Liulin a également été utilisé. Les résultats des mesures sont comparés avec ceux de calculs réalisés avec les codes CARI6 et EPCARD3.2. La période de monitorage représente environ 4,6 fois plus que la durée annelle habituelle de l'engagement d'un membre du personnel navigant (600 heures) : la dose efficace totale sur ces 2755 heures varie entre 11 et $12 \mathrm{mSv}$, suivant la méthode considérée. Dans un deuxième temps, les résultats du suivi dosimétrique individuel du personnel navigant obtenus au cours des dernières années sont résumés et l'évolution des tendances pour l'exposition du personnel des différentes compagnies est soulignée. La contribution de l'exposition du personnel navigant au rayonnement cosmique à la dose collective des travailleurs exposés en république tchèque se situe autour de $20 \%$.

1 Nuclear Physics Institute AS CR, Dept. of Radiation Dosimetry, Na Truhlářce 39/64, 18086 Prague 8, Czech Republic.

2 Czech Technical University, Dept. of Dosimetry and Application of Ionizing Radiation, Břehová 7, 11519 Prague 1, Czech Republic. 


\section{Introduction}

International Commission on Radiological Protection (ICRP) recommended in its publication 60 (ICRP, 1991) to take into account the radiation exposure due to the cosmic radiation onboard aircraft as a part of occupational exposure. This recommendation has been incorporated to the Czech regulation in 1997. Several series of onboard measurements have been realized since that time, mostly onboard of Czech Airlines (CSA) aircraft. Since 1998, routine individual dosimetry of Czech aircraft crew has been performed by calculations as generally recommended (EURADOS, 1996).

This contribution presents further results related to this topic. Long-term measurements onboard of an aircraft (Airbus 310-300) have been realized from May to December 2005, with both active (MDU-Liulin Si-diode based spectrodosimeter) and passive dosimeters (thermo-luminescent (TLD) and track etch detectors (TED)). Results obtained are presented and analyzed in comparison with data calculated by means of CARI6 (Friedberg et al., 1992) and EPCARD 3.2 (Schraube et al., 1999) codes. The calculation method has been used and validated for routine individual dose assessment on board of aircrafts in the Czech Republic because of the simple and cheap application compared with the personal dosimetry (especially due to the necessity to detect of the neutron component which requires more expensive device). Computer codes mentioned evaluate effective dose accurately enough during quiet solar conditions and for the major part of vertical cut-off rigidities. However, further measurements are necessary because the detailed knowledge of the difference between both methods is important for control and improving the routine method especially for the situation of solar particle events and Forbush decreases for which very few in-flight measurement data are still available. This analysis brings new data and contributes on this purpose. Moreover, the measurement campaign in flight altitudes enables comparison of responses of detectors that are calibrated in on-Earth conditions.

Results of individual monitoring of aircrew of Czech air companies obtained in last years using routine method based on the CARI6 code are finally presented; general tendencies of this type of occupational exposure are outlined.

\section{Long-term measurements onboard aircraft}

\subsection{Materials and methods}

\subsubsection{Dosimeters and detectors used}

MDU Si-diode based spectrodosimeter has been used in our laboratory to estimate the level of aircraft crew exposure since 2000 year, several long-term monitoring 
runs have been already realized (Spurný and Dachev, 2002, 2003). Details of the use of that equipment for the estimation of the onboard exposure have been already described in previous publications (Spurný and Dachev, 2003; Spurný and Ploc, 2005; Dachev et al., 2005); they can be summarized as follows:

(a) event deposition spectra in Si detectors are transformed to the onboard dose in $\mathrm{Si}, \mathrm{D}(\mathrm{Si})$;

(b) this dose is, on the base of calibrations realized in several on-Earth reference radiation fields, divided on the part corresponding mostly to the energy deposited due to non-neutron and/or neutron (and neutron-like) component of onboard radiation field;

(c) these partial $\mathrm{D}(\mathrm{Si})$ are converted to the ambient dose equivalent $\mathrm{H}^{*}(10)$ due to components mentioned using conversion factors determined in the CERF highenergy radiation fields and during the direct onboard common measurements of MDU equipment with tissue equivalent proportional counters (BottollierDepois et al., 2004).

As TLDs' response to neutrons represents in terms of dose equivalent less than 5\% comparing to low LET radiation (see Spurný, 2004), they have been used to estimate the contribution of non-neutron component to the ambient dose equivalent $\mathrm{H}^{*}(10)$. Three types of TLD's have been used: alumophosphate TL glass of Czech provenience (Trousil et al., 1984), $\mathrm{Al}_{2} \mathrm{O}_{3}: \mathrm{C}$ (Akselrod et al., 1990), and $\mathrm{CaSO}_{4}$ :Dy (Yamashita et al., 1971). Dosimeters were calibrated with ${ }^{60} \mathrm{Co}$ gamma radiation; the background accumulated during the time when aircraft was at ground was estimated on the base of MDU equipment data in the corresponding periods.

TED's on the base of polyallyldiglycolcarbonate (PADC) have been used to estimate the contribution of neutron (and neutron-like) component in two different ways:

(a) PADC materials have been mainly used as spectrometers of the linear energy transfer (LET). In this case, PADC's available from Page and those from Bristol University (Tastrak) were used, the procedure developed to establish LET spectra of registered, mostly secondary neutron-induced charged particles, has been described in several recently published papers, including the results of their use in radiotherapy particle beams and/or in space (Spurný et al., 2001, 2004; Spurný and Dudkin, 2002).

(b) PADC materials have been also used as neutron dosimeter. Page PADC material was exposed in contact with polyethylene proton radiator and have been treated by two methods of etching (Turek et al., 1993): short chemical pre-etching followed by high frequency electrochemical etching (ST procedure); and two frequency electrochemical etching, the first at lowfrequency followed by high-frequency etching ( $2 \mathrm{~F}$ procedure). TED as neutron 
dosemeter was calibrated for the use onboard aircraft in CERF high energy radiation field at CERN (Mitaroff and Sillari, 2002).

\subsubsection{Onboard aircraft exposure}

MDU equipment was onboard aircraft (Airbus 310-300) screwed on the inner wall close to the entrance to cockpit. Si-diode was oriented by the surface $10 \times 20 \mathrm{~mm}$ to sky. Passive detectors were scotched on the surface of the MDU equipment.

The onboard exposure started at the May 5th, 2005, the last flight (Prague-Bordeaux) was realized on the January 2nd, 2006. In total, 494 individual flights have been monitored during this period. From the view of geographical position, all flights can be separated into three groups (numbers of flights are in parenthesis): transatlantic (242); equator direction (126) - Dubai, Kuwait, Colombo, Egypt; short haul flights mostly in Europe (126).

\subsection{Results and discussion}

Integrated values of dose quantities as obtained by means of different detectors and/or evaluation procedures are presented in Table I.

TABLE I

Integral values of dose quantities established onboard an aircraft during the whole period of monitoring.

Valeurs intégrées des quantités dosimétriques mesurées à bord d'avion au cours de la campagne de mesure de 2005.

\begin{tabular}{ccccc}
\hline Method & Quality & \multicolumn{3}{c}{ Integrated exposure value, $\mathrm{mSv}$} \\
\cline { 3 - 5 } & & non-neutrons & neutrons & total \\
\hline CARI & $\mathrm{E}$ & - & - & $11.9^{1}$ \\
EPCARD & $\mathrm{E}$ & - & 4.90 & 11.7 \\
& $\mathrm{H}^{*}(10)$ & 4.31 & 5.72 & 10.0 \\
MDU & $\mathrm{H}^{*}(10)$ & $5.04 \pm 0.50^{2}$ & $6.20 \pm 0.92$ & $11.2 \pm 1.3$ \\
TLD - $\mathrm{Al}_{2} \mathrm{O}_{3}$ & $\mathrm{H}^{*}(10)$ & $4.21 \pm 0.30$ & - & - \\
TLD - AlP glass & $\mathrm{H}^{*}(10)$ & $4.40 \pm 0.18$ & - & - \\
\hline PADC - ND ST & $\mathrm{H}^{*}(10)$ & - & $4.11 \pm 0.70$ & - \\
PADC - ND 2F & $\mathrm{H}^{*}(10)$ & - & $6.35 \pm 0.76$ & - \\
\hline LET spectr. Page & $\mathrm{H}^{*}(10)$ & - & $3.6 \pm 0.6$ & - \\
LET spectr. Tastrak & $\mathrm{H}^{*}(10)$ & - & $4.3 \pm 0.7$ & - \\
\hline
\end{tabular}

${ }^{1}$ The uncertainties of calculated values are not fully known. The total uncertainty in the calculated values of effective dose are estimated to be about $30 \%$ (2s) (EURADOS, 2004)

$21 \mathrm{~s}($ reliability $67 \%$ ) is given. 
One can see there that:

(1) Generally, a good agreement can be stated for the results obtained for low LET component as well as for total values, when uncertainties corresponding to the method used are considered.

(2) The differences are a little bit more important for high LET component (neutrons), still being acceptable when reliability 95\% (2s) is considered. It can be expected because of:

- much more difficult calibration procedure and its interpretation due to largely high differences in response energy dependencies of methods, and

- much higher statistical uncertainties due to much lower signals for the neutron component.

(3) Few comments on the differences observed can be arisen:

- while MDU, PADC neutron detectors (ND), and calculations include in the results all neutron induced particles, LET spectrometers include only those with LET higher than registration threshold (about $10 \mathrm{keV} \mathrm{\mu m}^{-1}$ ) (Jadrníčková, 2006). Logically, the results obtained with LET spectrometers are in average lower;

- calculated values do not consider the influence of aircraft structure. It was estimated that the values for aircraft interior would be about $10 \%$ lower (Ferrari et al., 2005). Such differences could not be seen considering uncertainties of experimental values.

(4) It is not clear what would be the influence of angular dependence of the response. While Si-diode of MDU was oriented by $1 \times 2 \mathrm{~cm}^{2}$ plane to the sky, passive detectors were mostly oriented to the inside aircraft area. It could be excluded that angular effect is seen for TLD's, also for PADC NDs and higher energy neutrons would be below about 20\%. Angular dependence of MDU was specially studied. It was found that the responses in CERF field are within $\pm 12 \%$ for neutron component, $\pm 6 \%$ for total values. Tests onboard aircraft showed that the differences between readings with Si-diode oriented to sky or to aircraft floor are about 5\% (Spurný and Dachev, 2005).

It should be added, that $\mathrm{CaSO}_{4}$ :Dy TLDs have been exposed from the August 23rd. The reading corresponded to $(2.3 \pm 0.2) \mathrm{mSv}$ of $\mathrm{H}^{*}(10)$, in a good agreement with non-neutron component contribution measured for the same period by means of MDU equipment $(2.6 \pm 0.3) \mathrm{mSv}$.

\section{Individual monitoring of Czech aircraft crew}

\subsection{Procedure used}

The consecutive steps of the individual monitoring procedure are as follows (Spurný et al., 2005):

(1) Air company representatives prepare the data sets characterizing the aircraft and person traffic for a period; 
(2) sets are used to create an input set for the CARI6 code;

(3) the calculation of individual effective doses for each flight is performed, supposing slightly simplified flight profile:

- actual parameters: flight time, and the level of solar activity,

- model routes parameters, i.e. constant flight altitude for an aircraft type, and the constant times for the climbing to cruise altitude and the falling down to landing.

Previous comparisons showed that values of E calculated using model route are between 6 and 15\% lower than real E (Spurný et al. 2006);

(4) flight doses are automatically over crossed with aircrew data flight to obtain individual effective doses. These doses are transmitted to an air company.

NPI received the accreditation to perform the individual dosimetry of aircraft crew members since 1998 year, now it is prolonged up to the end of 2012.

\subsection{Results and discussion}

The distribution of average effective dose rates for individual aircrew members, company A, and 2004 year is presented in Figure 1. The relative annual effective dose distribution for three companies at 2003 year are compared in Figure 2, those for one company (A) and 2004 and 2005 years in Figure 3.

One can see there that:

1. Distribution of individual average effective dose rates (total $\mathrm{E}$ divided by the flight hours of members) is large (from 1.2 to $6.4 \mu \mathrm{Sv}$ per hour). Values of Erate vary according to flight type and directions and therefore dose assessment must be done individually and continuously.

2. Annual effective dose distributions are for all three companies similar, with rather large maximum about $2 \mathrm{mSv}$.

3. Company A decided to monitor all aircraft crew members to simplify the data transfer. That is the reason why there is some annual $\mathrm{E}$ also below $1 \mathrm{mSv}$. Nevertheless, even in such case, more than $90 \%$ of staff receives yearly more than $1 \mathrm{mSv}$.

Air transport in the Czech Republic is continuously increasing. Due to that, average annual effective dose is also regularly increasing. It is demonstrated in Figure 4 for the case of company A. Besides, the number of monitored persons increases even more rapidly. Due to that, collective $\mathrm{E}$ increased from about $1.5 \mathrm{mSv}$ at 1998 year up to about $3.6 \mathrm{mSv}$ for 2005 year. It represents closely to $20 \%$ of total occupational collective E in the Czech Republic (see Fig. 5). 


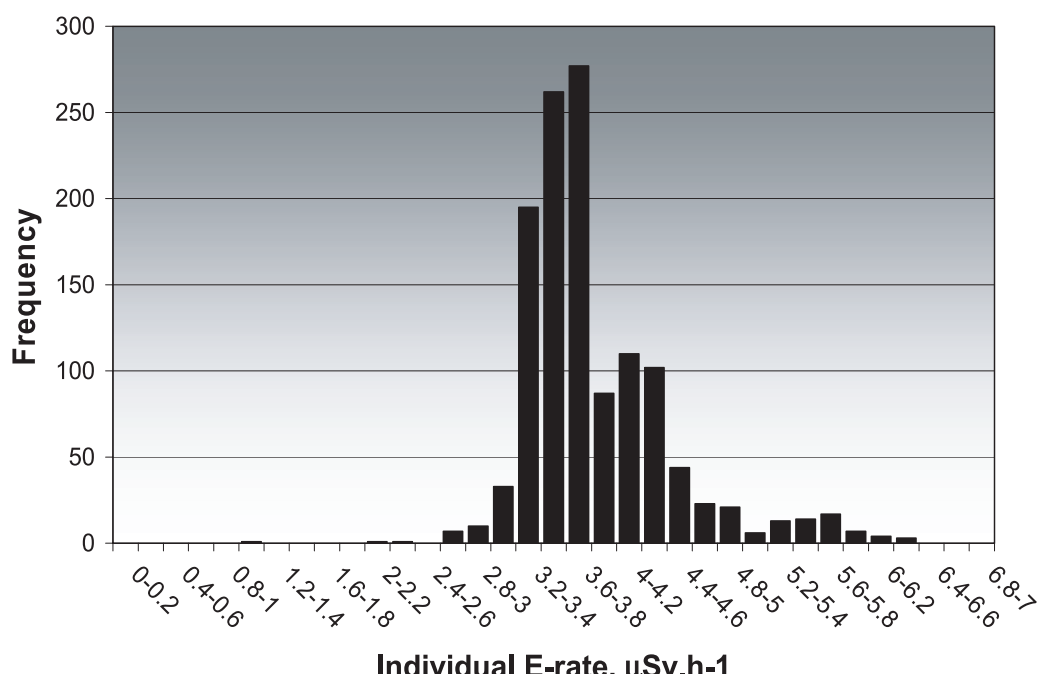

Figure 1 - Distribution of individual average effective dose rates in 2004 for the company A. Average effective dose rate is the effective dose average on one year for one person and divided by the number of hours of flight.

Distribution des valeurs individuelles moyennes des débits de dose efficace pour la compagnie A en 2004.

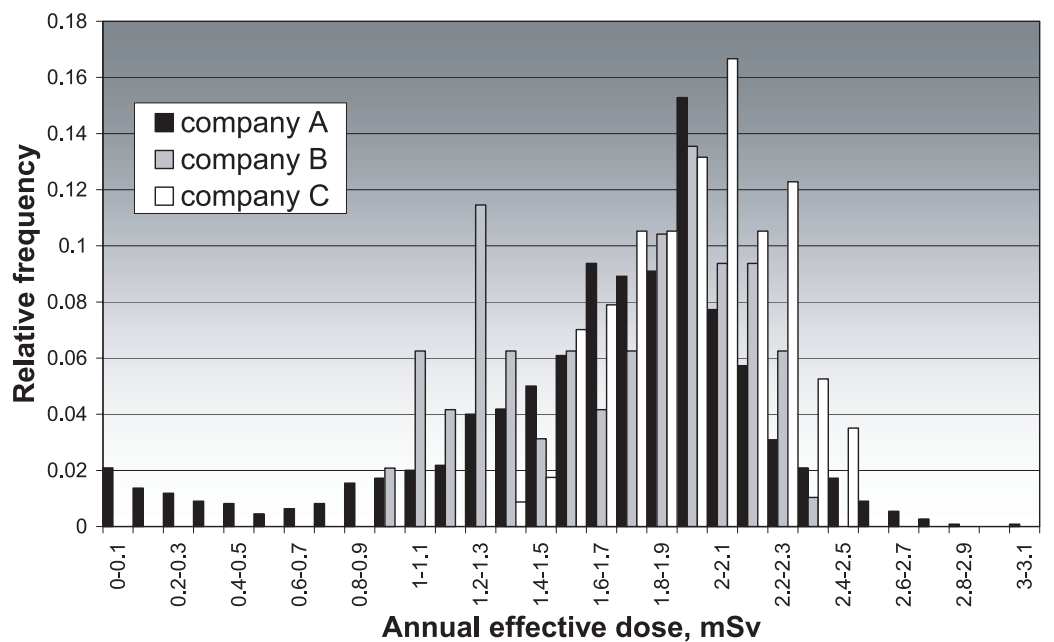

Figure 2 - Comparison of annual effective dose distributions of three air companies monitored in the Czech Republic at 2003 year (Spurný et al., 2005).

Comparaison des distributions de la dose efficace annuelle pour les trois compagnies tchèque pour l'année 2003. 


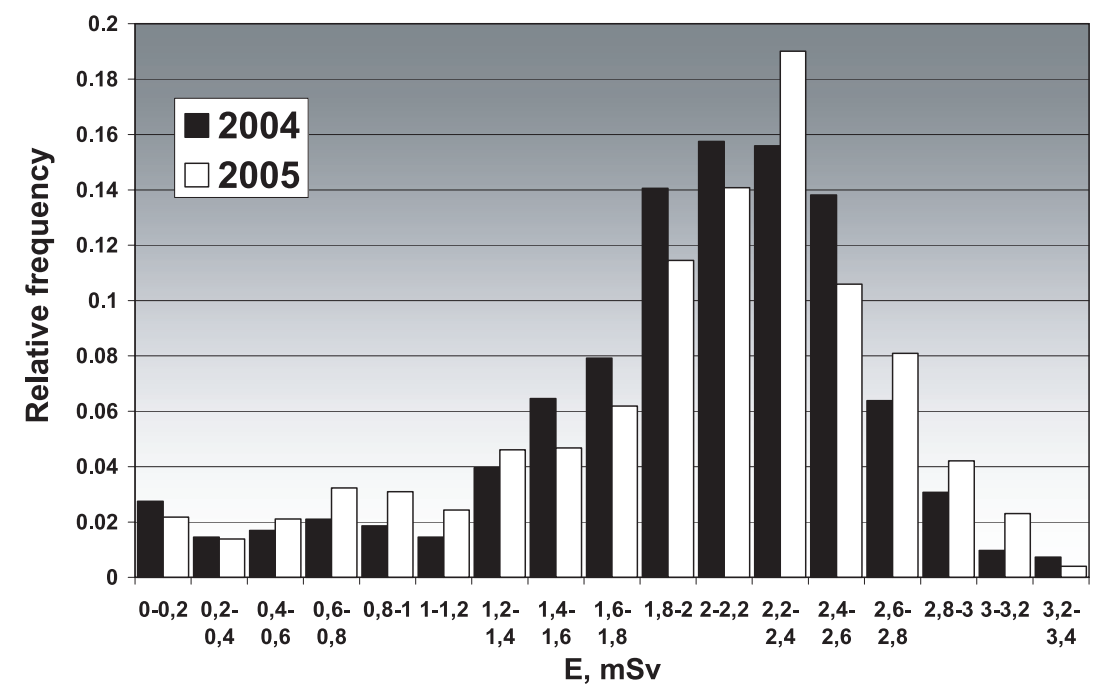

Figure 3 - Comparison of annual effective dose distributions for company A and 2004-2005 years.

Comparaison de la distribution de la dose efficace annuelle pour la compagnie A et les années 2004 et 2005 .

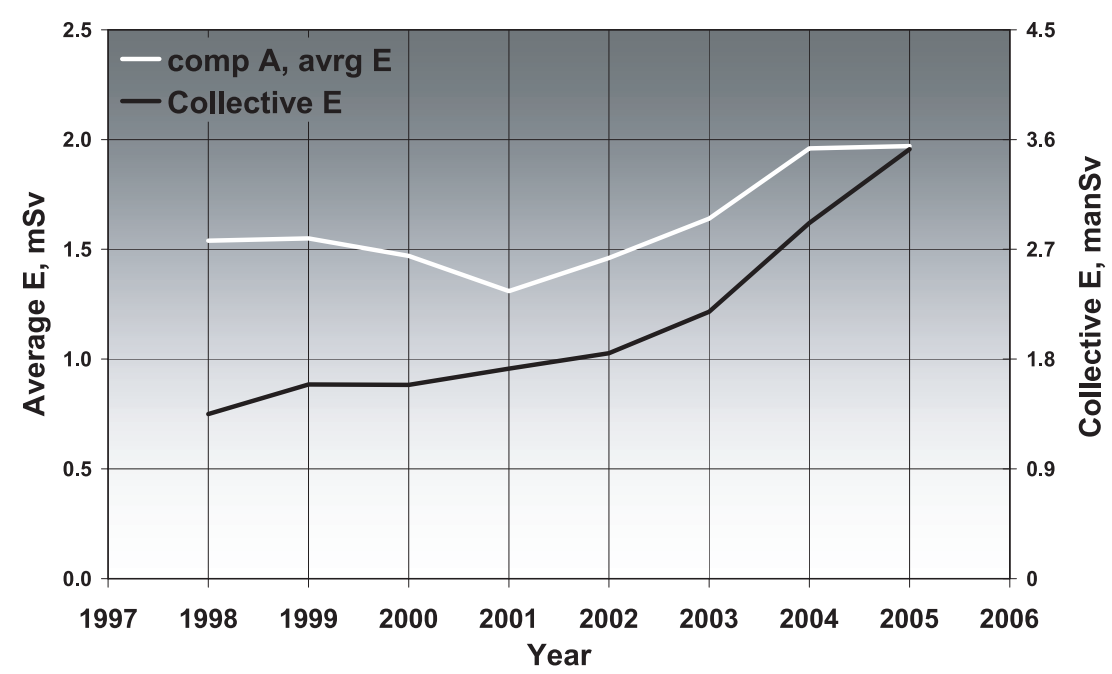

Figure 4 - Evolution of average annual E (company A) and total collective $E$ due to air transport in the Czech Republic in the period 1998-2005.

Comparaison de la dose efficace annuelle moyenne pour la compagnie A et de la dose efficace collective du personnel navigant tchèque entre 1998 et 2005. 


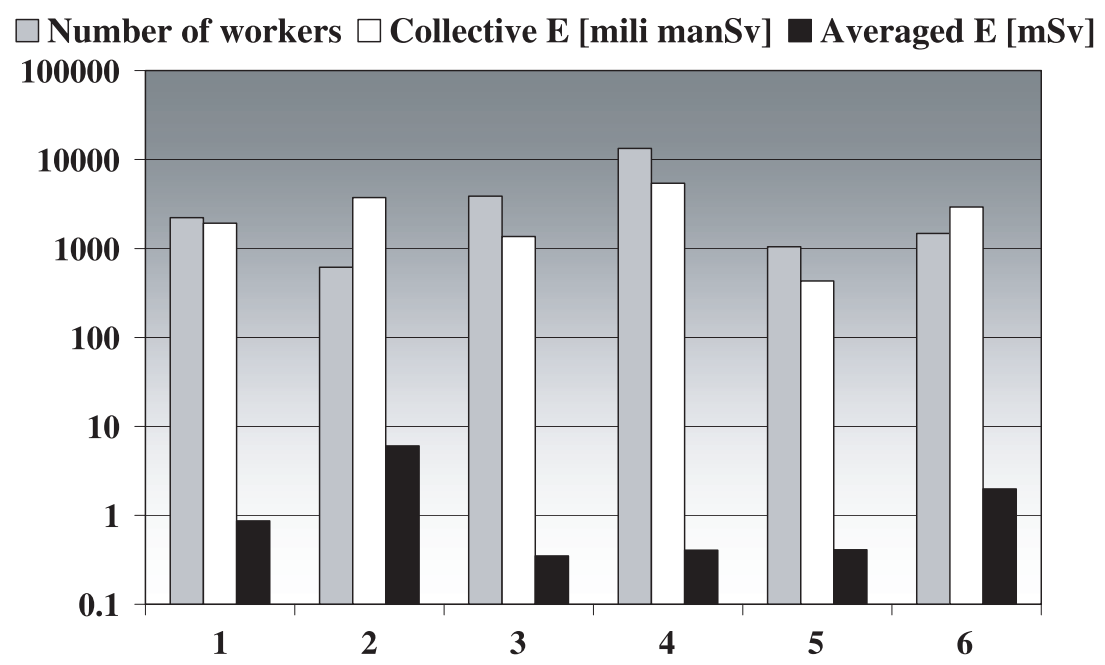

1: Industry, 2: Uranium Mining, 3: Nuclear Power Plants, 4: Health Care, 5: Control, Inspection, Service, 6: Aircrew.

Figure 5 - Comparison of occupational exposure in the Czech Republic (year 2004).

Répartition de l'exposition professionnelle en république tchèque pour l'année 2004.

Acknowledgements. The authors are obliged to K. Turek for the submission of results obtained with PADC neutron dosimeters. The studies performed have been partially supported through the grant of the GA of the Czech Republic No. 202/04/0795.

\section{REFERENCES}

Akselrod M.S., Kortov V.S., Kravetsky D.J., Gottlib V.I. (1990) Highly Sensitive Thermo-luminescent Anion-Defect a- $\mathrm{Al}_{2} \mathrm{O}_{3}: \mathrm{C}$ Single Crystal Detectors, Radiat. Prot. Dosim. 33, 119-122.

Bottollier-Depois J.-F. et al. (2004) Exposure of aircraft crew to cosmic radiation: On-board intercomparison of various dosimeters, Radiat. Prot. Dosim. 110, 411-415.

Dachev Ts., Spurný F., Reitz G., Domov B.T., Dimitrov P.G., Matviichuk Y.N. (2005) Simultaneous investigation of galactic cosmic rays on aircraft and on International Space Station, Adv. Space Res. 36, 1665-1670

EURADOS (1996) Exposure of aircrew to cosmic radiation, I.R. McAulay, D.T. Bartlett, G. Dietre, H.G. Menzel, K. Schnuer, H.J. Schrewe (Eds.), Luxembourg, ISBN 92-827-7994-7.

EURADOS (2004) Cosmic radiation exposure of aircraft crew. Compilation of measured and calculated data, Radiat. Prot. 140, 1-271.

Ferrari A., Pelliccioni M., Villari P. (2005) Mathematical model of aircraft for evaluating the effects of shielding structure on aircrew exposure, Radiat. Prot. Dosim. 116, 331-335. 
Friedberg W., Snyder W., Faulkner D.N. (1992) Radiation exposure of air carrier crew member, US FAA Report DOT/FAA/AM-92-2.

ICRP Publication 60 (1991) Recommendations of the International Commission on Radiological Protection, Ann. ICRP 26.

Jadrníčková I. (2006) Spectrometry of linear energy transfer and its use in radiotherapy and radiation protection in high-energy particle fields, Ph.D. dissertation thesis, Czech Technical University, Prague.

Mitaroff A., Silari M. (2002) The CERN-EU high-energy reference field (CERF) facility for dosimetry at commercial flight altitudes and in space, Radiat. Prot. Dosim. 102, 7-22.

Schraube H., Mares V., Roessler S., Heinrich W. (1999) Experimental verification and calculation of aviation route dosis, Radiat. Prot. Dosim. 86, 309-315.

Spurný F. (2004) Response of thermoluminescent detectors to charged particles and to neutrons, Radiat. Meas. 38, 407-412.

Spurný F., Dachev Ts. (2002) Aircrew onboard Dosimetry with a Semiconductor Spectrometer, Radiat. Prot. Dosim. 100, 525-529.

Spurný F., Dachev Ts. (2003) Long-term monitoring of the onboard aircraft exposure level with Sidiode based spectrometer, Adv. Space Res. 32, 53-58.

Spurný F., Dachev Ts. (2005) Aircrew exposure assessment by means of a Si-diode spectrometer, Radioact. Environm. 7, 871-875

Spurný F., Dudkin V.E. (2002) Dosimetry and microdosimetry characteristics measured on board the MIR station during the 28th basic expedition, Radiat. Measur. 35, 539-543.

Spurný F., Ploc O. (2005) Routine individual dosimetry of aircraft crew exposure. Czech experience and results since 1998, Radiat. Prot. Dosim., in print, DOI: 10.193/rpd/nc1559.

Spurný F., Bottollier-Depois J.-F., Vlek B. (2001) Spectrometry of the LET with Track Etched Detectors - Correlation with Proportional Counter Measured Spectra, Radiat. Meas. 34, 193198.

Spurný F., Molokanov A.G., Bamblevski V.P. (2004) Spectrometry of linear energy transfer, its development and use for proton radiation therapy, Radiat. Prot. Dosim. 110, 675-679.

Spurný F., Trompier F., Bottollier-Depois J.-F. (2005) To the angular dependence of Si-energy deposition spectrometers response at several radiation sources, Radiat. Meas. 39, 323-327.

Spurný F., Malušek A., Kováŕ I., Oríková H., Ploc O. (2006) Aircraft crew individual dosimetry of Czech air companies: 1998 - 2004 overview, Nucl. Energy Saf. 14, 172-177.

Trousil J. et al. (1984) Basic dosimetric characteristics of the Czechoslovak thermoluminescent and neutron dosimeters, Kernenergie 27, 246-254.

Turek K., Spurný F., Alberts W.G. (1993) On the optimization of the etching of CR 39 as fast neutron dosemeter, Nucl. Tracks Radiat. Meas. 21, 299-302.

Yamashita Y., Nada N., Onishi H., Kitamura S. (1971) Preparation and properties of new $\mathrm{CaSO}_{4}: \mathrm{Dy}$ [Tm] thermoluminescent detectors, Health Phys 21, 295-299. 